\title{
Spisulosine (ES-285) given as a weekly three-hour intravenous infusion: results of a phase I dose-escalating study in patients with advanced solid malignancies
}

\author{
P. Schöffski · H. Dumez $\cdot$ R. Ruijter $\cdot$ B. Miguel-Lillo $\cdot$ \\ A. Soto-Matos $\cdot$ V. Alfaro $\cdot$ G. Giaccone
}

Received: 23 December 2010/Accepted: 4 March 2011/Published online: 5 April 2011

(C) Springer-Verlag 2011

\begin{abstract}
Purpose Spisulosine is a marine compound that showed antitumor activity in preclinical studies. We report results of a phase I trial performed in patients with advanced solid tumors with the marine compound, with the aim to determine the maximum tolerated dose (MTD) of a weekly 3-h intravenous (iv.) infusion, and to evaluate the safety, efficacy, and pharmacokinetics (PK) of the compound.

Patients and methods Two centers contributed 25 patients to the trial, and 7 dose levels were explored.

Results In dose levels ranging from 4 to $128 \mathrm{mg} / \mathrm{m}^{2} /$ day, no dose-limiting toxicities (DLT) were observed. One patient had DLT at $200 \mathrm{mg} / \mathrm{m}^{2}$, a reversible grade 3 ALT increase. The MTD was not reached due to early termination of the Spisulosine trial program but is considered to be likely in the range of $200 \mathrm{mg} / \mathrm{m}^{2}$ for this schedule. Drug-related adverse reactions included mild to moderate nausea, pyrexia, injection site reactions, and vomiting. One case of grade 4 peripheral motor and sensory neuropathy
\end{abstract}

P. Schöffski $(\bowtie) \cdot$ H. Dumez

Department of General Medical Oncology, University Hospitals Leuven, Leuven Cancer Institute, Catholic University Leuven, Herestraat 49, 3000 Leuven, Belgium

e-mail: patrick.schoffski@uzleuven.be

R. Ruijter · G. Giaccone

Department of Medical Oncology, Free University Medical

Center, Amsterdam, The Netherlands

B. Miguel-Lillo · A. Soto-Matos · V. Alfaro

PharmaMar, S.A., Colmenar Viejo, Madrid, Spain

Present Address:

G. Giaccone

Medical Oncology Branch, National Cancer Institute,

National Institutes of Health, Bethesda, MD, USA associated with general weakness and pain was observed during treatment cycle 4 and possibly contributed to the death of the patient. Grade 3 laboratory abnormalities included anemia and lymphopenia and increases in liver enzymes (alkaline phosphatase, transaminases, and bilirubin). Objective responses were not observed, and only four patients had short-lasting stable disease $(<3$ months). The PK data indicated a wide distribution, a long residence time, and dose proportionality of the agent.

Conclusions Hepato- and neuro-toxicity are schedule independent dose-limiting adverse events for this marine compound, as illustrated by this and other early clinical trials.

Keywords ES-285 - Spisulosine - Phase I - Marine compounds · Pharmacokinetics · Hepatotoxicity · Neurotoxicity

\section{Introduction}

Spisulosine (ES-285, PM95118, IL0111) is the analog of a phospholipid sphingosine, which was isolated from the marine mollusk Spisula polynyma [1] (Fig. 1,2). Preclinical studies indicated strong antineoplastic potential against a variety of malignancies, ranging from hematological malignancies to solid tumors [1-3]. The mechanism of action of Spisulosine, which induces programmed cell death in vitro, is still speculative. GTP binding protein regulating actin stress fibers has been proposed as a potential molecular target, as tumor cells exposed to the agent show suggestive phenotypic changes and expression profiling data indicated modulation of genes related to the actin cytoskeleton [4]. Spisulosine seems also to be capable of activating caspases 3 and 12, the poly ADP-ribose 


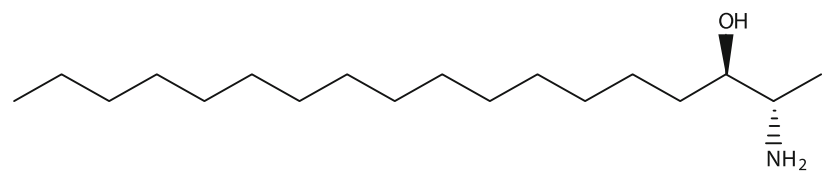

Fig. 1 Chemical structure of Spisulosine (molecular formula $\left.\mathrm{C}_{18} \mathrm{H}_{39} \mathrm{NO}\right)$

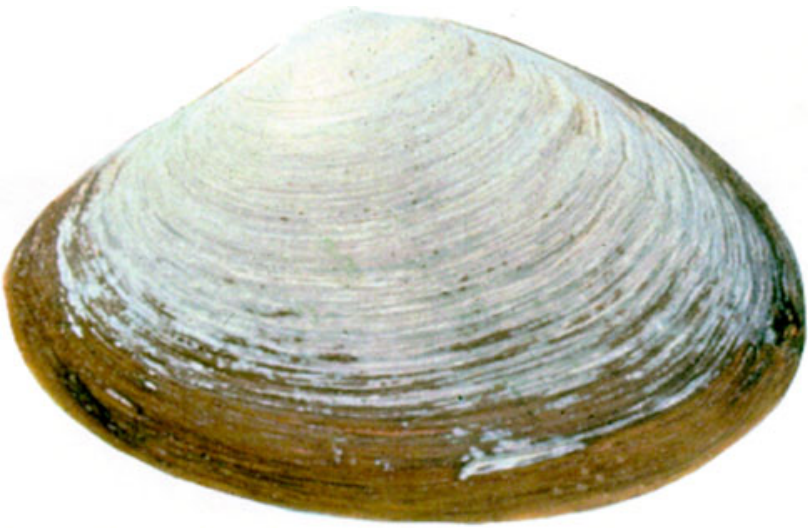

Fig. 2 Spisula polynyma (Alaska)

polymerase pathway, and p53 phosphorylation [5]. Four different administration schemes of single-agent Spisolusine have been assessed in separate clinical phase I studies [6-9]. The current trial evaluated a 3-h infusion given i.v. every week in 3-week intervals, with the objective to identify the MTD, to establish the safety profile of this schedule, to assess preliminary signs of antitumor activity, and to assess the PK profile of this novel compound.

\section{Patients and methods}

Patient selection

Patients had a histologically confirmed solid tumor and had exhausted standard treatment options, were 18-70 years old, had no acute adverse effects from prior treatments, a life expectancy $\geq 12$ weeks, measurable or non-measurable disease according to RECIST [10], Eastern Cooperative Oncology Group performance status of $0-2$ and good organ function (creatinine $<1.5 \mathrm{mg} / \mathrm{dl}$ or calculated creatinine clearance $>60 \mathrm{ml} / \mathrm{min}$; alanine aminotransferase [ALT] and aspartate aminotransferase [AST] $\leq 2.5 \times$ upper limit of normal [ULN]; bilirubin $\leq 1.5 \times \mathrm{ULN}$ ); absolute neutrophil count $[\mathrm{ANC}] \geq 1.5 \times 10^{9} / \mathrm{l}$, platelets $\geq 100 \times 10^{9} / \mathrm{l}$ ); left ventricular ejection fraction $\geq 50 \%$ ).

In case of clinically relevant preexisting comorbidity, increased cardiac risk, brain metastasis or if they had received chemotherapy, radiotherapy or biological therapy within 4 weeks or immunosuppressors within 3 weeks previous to enrollment, patients were excluded from trial participation. Pregnant or lactating women were not entered. All patients provided written informed consent, and ethics committee approval was obtained in both involved clinical sites.

\section{Study design}

Patients were recruited from centers in Belgium (University Hospital Gasthuisberg, Leuven) and in the Netherlands (Free University Hospital, Amsterdam). Spisulosine, supplied as $50 \mathrm{mg}$ of lyophilized powder by PharmaMar S.A., Spain, was reconstituted in $5 \mathrm{ml}$ of water and made up to $250 \mathrm{ml}$ with $5 \%$ dextrose and given weekly as a 3-h i.v. infusion for at least one three-week cycle [11, 12]. Dose escalation was performed in subsequent cohorts of 3 to a maximum of 6 patients. The starting dose was $4 \mathrm{mg} / \mathrm{m}^{2} /$ day (total dose of $12 \mathrm{mg} / \mathrm{m}^{2}$ per cycle), corresponding to $30 \%$ of the MTD in mice. Interpatient dose escalation up to $200 \mathrm{mg} / \mathrm{m}^{2} /$ day was considered by protocol. The dose was doubled per cohort until dose-limiting toxicity (DLT) was observed. The DLT window was the first 6 weeks of treatment (first two three-week cycles), and DLT was defined as a treatment delay $>2$ weeks, ANC $<0.5 \times 10^{9} / 1$ for $>5$ days or $<1.0 \times 10^{9} / 1$ with fever, platelets $<25 \times 10^{9} / \mathrm{l}$, a relative decrease in LVEF $\geq 20 \%$ compared to the pre-study assessment, or any other grade $3 / 4$ nonhematological adverse event except for non-adequately treated nausea/vomiting. In the absence of DLT during the first two treatment cycles, three patients were treated per dose level. A 3-week safety interval was mandated by protocol before the second and third patient of a cohort could start treatment. If DLT occurred, up to three additional patients were treated. If two or more experienced DLT, this dose level was considered the MTD for this schedule. The recommended dose for further clinical studies was defined as the highest dose level where DLT was observed in less than two out of six trial participants.

\section{Clinical assessments}

Routine medical examinations were performed at the start of every cycle and before administering the weekly drug infusion. Electrocardiogram, blood counts, and serum chemistry including cardiac enzymes were performed weekly. Tumor response was evaluated every 6 weeks according to RECIST [10], adverse events were scored continuously following the National Cancer Center Common Toxicity Criteria (NCI-CTC) v. 2.0. 


\section{Pharmacokinetics}

Heparinized blood samples $(5 \mathrm{ml})$ were collected according to protocol and analyzed centrally with a validated high-performance liquid chromatography system coupled with electrospray ionization tandem mass spectrometry (1.0 ng/ml limit of quantification) [13].

WinNonlin software (version 5.0.1) with standard noncompartmental methods was used to calculate the area under the plasma concentration curve from time 0 to the last quantifiable concentration $\left[\mathrm{AUC}_{\text {last }}\right]$, peak plasma concentration $\left(C_{\max }\right)$, total body clearance $(\mathrm{CL})$, terminal half-life $\left(t_{1 / 2}\right)$, and volume of distribution $(\mathrm{Vz})$, and the statistical analysis was done with $\mathrm{SAS}^{\circledR}$ version 8.2 (SAS Institute, Cary, NC).

\section{Results}

Patient characteristics

Twenty-five patients were treated between May 2003 and November 2005, with 23/25 being evaluable for the safety and efficacy endpoints of the trial. Patient characteristics are shown in Table 1. Malignant melanoma $(n=5$ patients), colorectal cancer $(n=4)$, prostate cancer $(n=2)$, and chondrosarcoma $(n=2)$ were the most common entities. All patients had metastatic disease at study entry, and all but one had received prior chemotherapy $(96 \%)$, with a median of three lines per patient (range, 1-10).

Table 1 Patient characteristics

\begin{tabular}{ll}
\hline Characteristics & $N$ \\
\hline No. of patients & 25 \\
Male/female & $17 / 8$ \\
Median age in years (range) & $54(21-74)$ \\
ECOG performance status 0/1/2 & $9 / 14 / 2$ \\
Primary cancer & \\
Melanoma & 5 \\
Colorectal & 4 \\
Chondrosarcoma & 2 \\
Prostate & 2 \\
Other ( $n=1 /$ tumor type) & 12 \\
Metastatic & 25 \\
Median $N$ of involved sites (range) & $3(1-6)$ \\
Prior therapy & \\
Chemotherapy & 24 \\
Median $N$ of lines (range) & $3(1-10)$ \\
\hline
\end{tabular}

ECOG Eastern cooperative oncology group
Dose escalation and DLTs

All 7 dose levels planned according to protocol were visited, and doses were escalated until $200 \mathrm{mg} / \mathrm{m}^{2} /$ day (Table 2). Sixty-one cycles were administered with a median of 2 cycles per patient (range, 1-5). Treatment was discontinued due to disease progression ( $n=22$ patients), adverse events $(n=2)$, or withdrawal of consent $(n=1)$. The median cumulative administered dose was $160 \mathrm{mg} / \mathrm{m}^{2}$ (range, $8-2,400 \mathrm{mg} / \mathrm{m}^{2}$ ), with a median relative dose intensity of $83 \%$ (range, 33-102\%).

One patient experienced a DLT, a reversible grade 3 increase in serum ALT in the first cycle at the highest dose level of $200 \mathrm{mg} / \mathrm{m}^{2} /$ day (Table 2). One patient experienced grade 4 sensory and motor neuropathy during cycle 4, which possibly contributed to the patient's subsequent death. An autopsy was not performed. MTD was not formally reached due to early study termination, following a consensual agreement between the sponsor and investigators involved in the Phase I program of Spisulosine, based on fatal neurotoxicity experienced by a patient in a parallel trial, the observation of grade 4 neuropathy during consecutive treatment cycles of patients in our trial and limited evidence of antitumor activity in this and other studies. The MTD is likely in the range of $200 \mathrm{mg} / \mathrm{m}^{2} /$ day for the weekly 3-h schedule, with one DLT observed in cycle 1 in this prematurely closed study.

Overall tolerability

The most frequent adverse events were nausea, pyrexia, injection site reactions/phlebitis, and vomiting (20, 20, 20, and $16 \%$ of patients, respectively; Table 3). All drugrelated AEs were mild (grade 1 or 2), with the exception of a patient who developed grade 4 peripheral motor and grade 4 sensory neuropathy during cycle 4 of treatment.

The most frequent hematological events were anemia (all patients, $20 \%$ with grade 3) and lymphopenia (72\% of patients, $20 \%$ with grade 3 ). The most common biochemical abnormalities were increases in serum alkaline phosphatase and transaminase levels. The incidence of other biochemical abnormalities was low. Three patients had grade 3 AST increases, and 2 patients had grade 3 ALT increases, one of these events qualifying as the only DLT observed in this trial.

Drug-related serious adverse events included one patient with pyrexia and one patient with neuropathy. The first patient was a 61-year-old male with metastatic colorectal cancer who developed fever up to 40 degrees Celsius after the first administration of Spisulosine $32 \mathrm{mg} / \mathrm{m}^{2}$; he recovered without sequelae and received further infusions without similar complications. The second patient was a 69-year-old male with metastatic melanoma who received 
Table 2 Dose escalation and dose-limiting toxicity for Spisulosine

\begin{tabular}{lllll}
\hline $\begin{array}{l}\text { Dose level } \\
\left(\mathrm{mg} / \mathrm{m}^{2} / \text { day }\right)\end{array}$ & $\begin{array}{l}\text { No. of } \\
\text { patients }\end{array}$ & $\begin{array}{l}\text { No. of cycles, } \\
\text { median (range) }\end{array}$ & $\begin{array}{l}\text { Days on study, } \\
\text { median (range) }\end{array}$ & $\begin{array}{l}\text { No. of patients } \\
\text { with DLT }\end{array}$ \\
\hline 4 & 3 & $2(2-2)$ & $27(26-42)$ & 0 \\
8 & 5 & $2(1-3)$ & $27(7-49)$ & 0 \\
16 & 3 & $2(2-4)$ & $28(28-70)$ & 0 \\
32 & 3 & $2(2-2)$ & $28(28-28)$ & 0 \\
64 & 3 & $4(2-5)$ & $70(28-92)$ & 0 \\
128 & 3 & $3(2-4)$ & $49(29-77)$ & 0 \\
200 & 5 & $2(1-5)$ & $28(7-91)$ & 1 \\
Total & 25 & 61 & $28(7-92)$ & 1 \\
\hline
\end{tabular}

Table 3 Grade 3 treatment-emergent toxicities per patient

\begin{tabular}{|c|c|c|c|c|c|c|c|}
\hline \multirow{2}{*}{$\begin{array}{l}\text { Dose level } \\
\left(\mathrm{mg} / \mathrm{m}^{2}\right)\end{array}$} & \multirow{2}{*}{$\begin{array}{l}\text { No. of } \\
\text { patients } \\
\text { treated }\end{array}$} & \multicolumn{6}{|c|}{ No. of patients } \\
\hline & & Anemia & Lymphopenia & $\begin{array}{l}\text { AST } \\
\text { increase }\end{array}$ & ALT increase & $\begin{array}{l}\text { AP } \\
\text { increase }\end{array}$ & $\begin{array}{l}\text { Bilirubin } \\
\text { increase }\end{array}$ \\
\hline $4-32$ & 14 & $3(21 \%)$ & $3(21 \%)$ & - & - & $3(21 \%)$ & $2(14 \%)$ \\
\hline 64 & 3 & $1(33 \%)$ & $1(33 \%)$ & $1(33 \%)$ & $1(33 \%)$ & $1(33 \%)$ & - \\
\hline 128 & 3 & - & - & - & - & - & - \\
\hline 200 & 5 & $1(20 \%)$ & $1(20 \%)$ & $2(40 \%)$ & $1(20 \%)$ & - & $1(20 \%)$ \\
\hline Total & 25 & $5(20 \%)$ & $5(20 \%)$ & $3(12 \%)$ & $2(8 \%)$ & $3(12 \%)$ & $3(12 \%)$ \\
\hline
\end{tabular}

In addition to these grade 3 laboratory events, a case of grade 4 peripheral motor neuropathy and grade 4 peripheral sensory neuropathy was observed in one patient in the $128 \mathrm{mg} / \mathrm{m}^{2}$ dose cohort

Grade $1 / 2$ clinical adverse events included injection site reactions (20\% of all patients), pyrexia (20\%), nausea (20\%), vomiting (16\%), asthenia $(12 \%)$, myalgia (8\%), limb pain $(8 \%)$, back pain $(4 \%)$, dysgeusia $(4 \%)$, headache $(4 \%)$, paresthesia $(4 \%)$, and hot flushes $(4 \%)$

Table 4 Summary of pharmacokinetic parameters on day 1

\begin{tabular}{llllrrrr}
\hline $\begin{array}{l}\text { Dose } \\
\left(\mathrm{mg} / \mathrm{m}^{2} / \text { day }\right)\end{array}$ & $\begin{array}{l}\text { No. of } \\
\text { evaluable patients }\end{array}$ & \multicolumn{1}{l}{$\begin{array}{l}C_{\max } \\
(\mathrm{ng} / \mathrm{ml})\end{array}$} & $\begin{array}{l}\text { AUClast } \\
(\mathrm{h} \mathrm{ng} / \mathrm{ml})\end{array}$ & \multicolumn{1}{c}{$\begin{array}{l}\text { AUC } \\
(\mathrm{h} \mathrm{ng} / \mathrm{ml})\end{array}$} & \multicolumn{1}{l}{$\begin{array}{l}\mathrm{CL} \\
(\mathrm{L} / \mathrm{h})\end{array}$} & $\begin{array}{l}\mathrm{Vz} \\
(\mathrm{L})\end{array}$ & \multicolumn{1}{c}{$\begin{array}{l}t_{1 / 2} \\
(\mathrm{~h})\end{array}$} \\
\hline 4 & 2 & $9.3(17.4)$ & $24.3(5.2)$ & $31.7(33.2)$ & $258.4(34.6)$ & $1,521.5(114.9)$ & $5.2(124.7)$ \\
8 & 5 & $68.0(95.7)$ & $204.5(59.8)$ & $302.1(70.7)$ & $92.8(93.4)$ & $2,554.3(93.1)$ & $41.2(94.4)$ \\
16 & 3 & $41.1(8.4)$ & $170.0(28.4)$ & $272.5(38.1)$ & $113.0(40.6)$ & $7,152.3(14.6)$ & $50.8(51.3)$ \\
32 & 3 & $58.9(32.3)$ & $167.4(31.3)$ & $171.4(30.9)$ & $400.0(43.1)$ & $1,205.6(47.1)$ & $2.1(4.0)$ \\
64 & 3 & $168.0(1.6)$ & $522.6(25.2)$ & $575.5(30.3)$ & $224.5(33.9)$ & $7,576.5(99.7)$ & $32.2(123.8)$ \\
128 & 3 & $379.7(18.1)$ & $1,292.8(11.5)$ & $1,416.2(13.5)$ & $169.2(22.4)$ & $11,299.0(95.2)$ & $48.7(103.3)$ \\
200 & 4 & $658.0(12.5)$ & $2,926.2(54.1)$ & $3,287.6(57.9)$ & $142.4(40.9)$ & $13,462.5(78.6)$ & $60.9(58.5)$ \\
\hline
\end{tabular}

Values are mean (coefficient of variation, \%)

$A U C$ Area under the plasma concentration-time curve, $C I$ confidence interval, $C L$ clearance, $C_{\max }$ maximum plasma concentration, $t_{1 / 2}$ terminal phase half-life, $V z$ volume of distribution

8 infusions of the agent at a dose of $128 \mathrm{mg} / \mathrm{m}^{2}$. He developed grade 1 numbness of the face, hands, and feet prior to the eighth weekly infusion; his symptoms worsened rapidly with the occurrence of neuropathy, pain, and general weakness to grade 4 , which ultimately also contributed to his subsequent death according to the investigator's assessment. The patient had no other known risk factors for neuropathy, had no relevant comorbidities and did not receive any other drug associated with potential neurotoxicity. The sensor and motor neuropathy of this patient did not respond to treatment with vitamin B12 or pregabalin. At time of onset of the neuropathy, he had no evidence of disease progression, but the best overall response to spisulosine was progressive disease. 
Fig. 3 a Representative concentration-time plot for Spisulosine administered on day 1 as a 3 -h intravenous infusion $\left(200 \mathrm{mg} / \mathrm{m}^{2}\right)$. b (I) Peak plasma concentration $\left(C_{\max }\right)$ versus total dose; (II) Area under the curve versus total dose

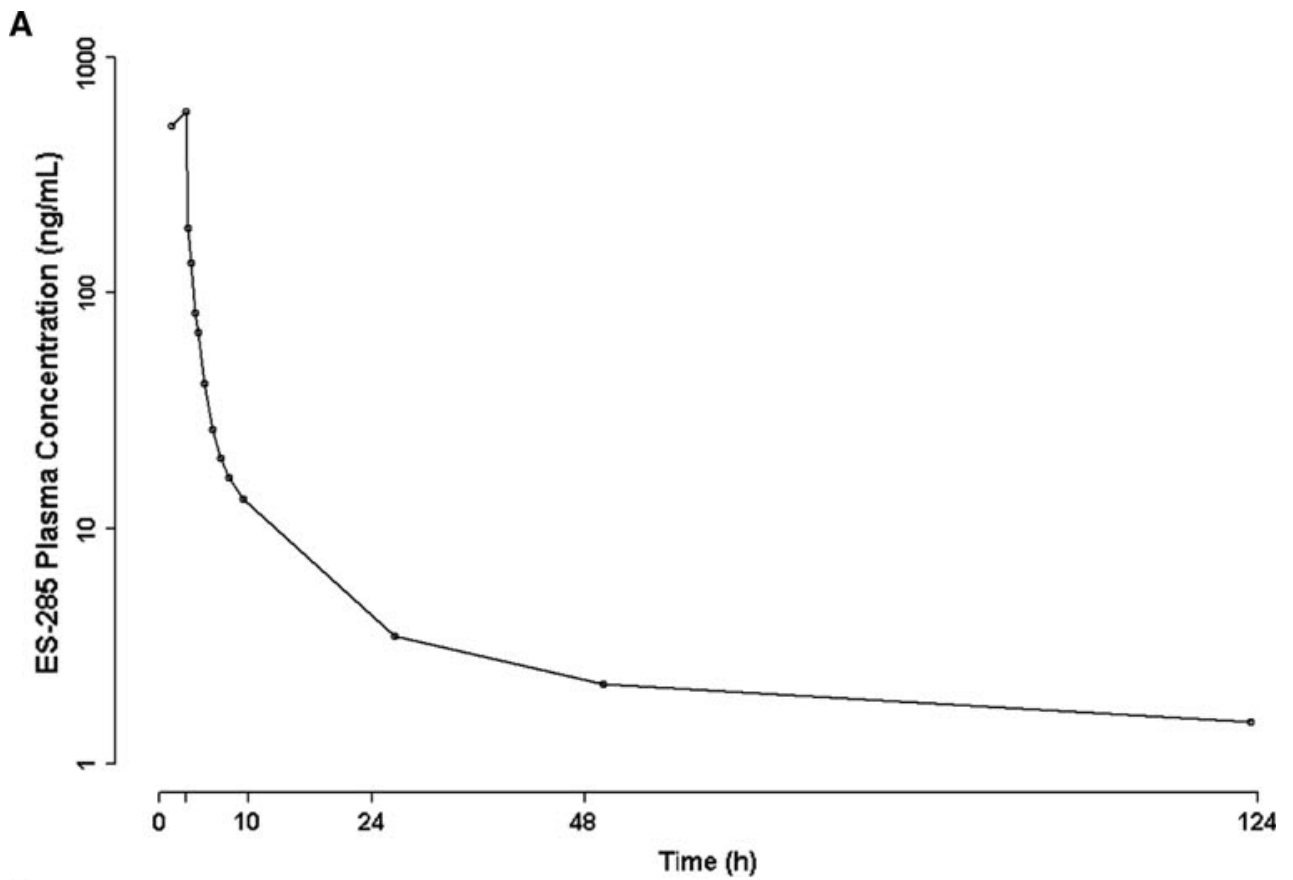

B
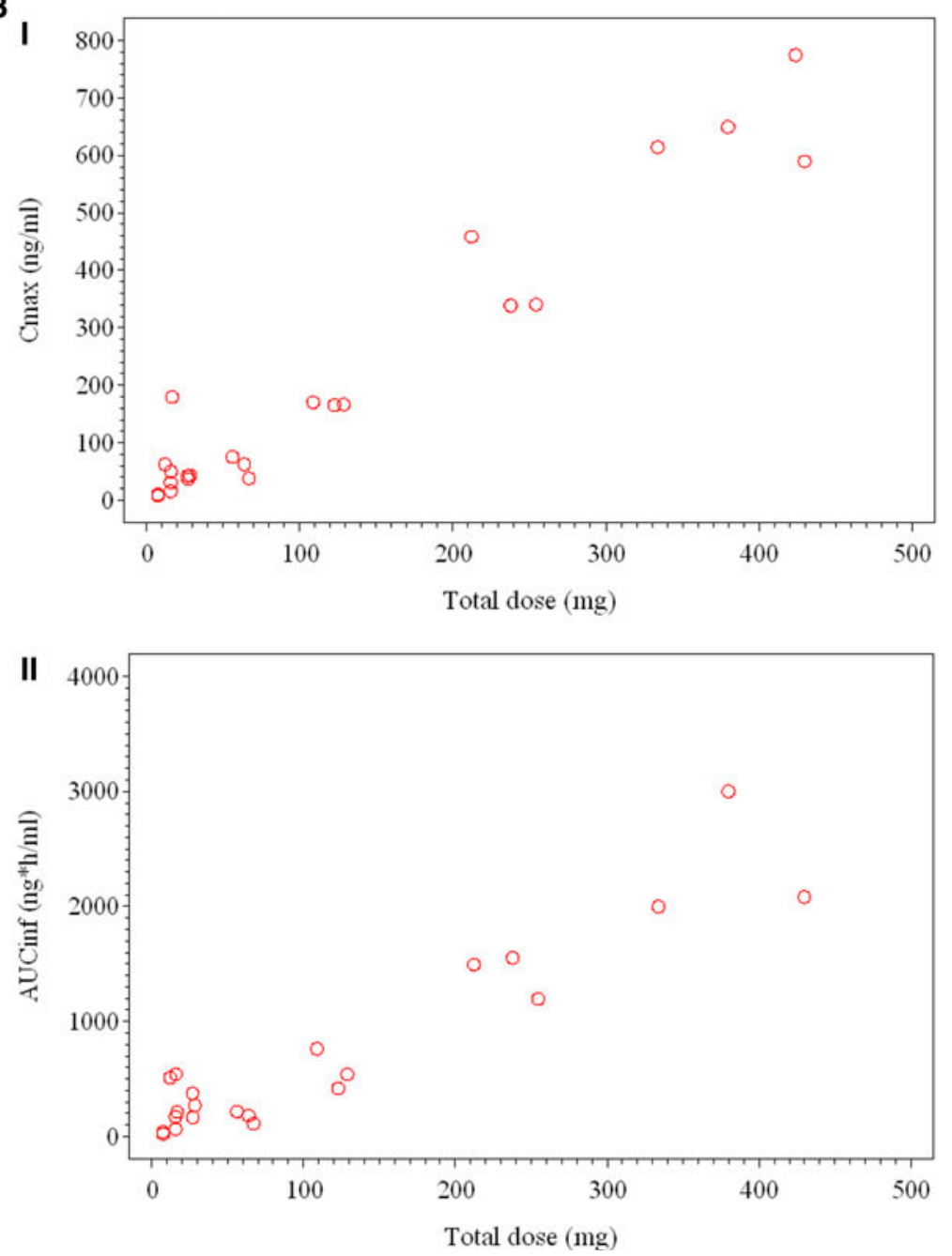
Antitumor activity

No objective responses were seen among twenty-three evaluable patients. Four patients (two patients with melanoma, and one each with ovarian cancer and chondrosarcoma) showed stable disease, lasting for less than 3 months.

\section{Pharmacokinetics}

Twenty-three patients were evaluated for PK (Table 4), which was characterized by a wide distribution (dosedependent median volume of distribution [ $V_{\mathrm{SS}}$ ] ranging between 1,638 and 6,505 liters) and a long body residence with a median $t_{1 / 2}$ of $61 \mathrm{~h}$ (range, 28-94 h). PK indicated dose linearity, but the sample size was too limited to draw definitive conclusions (Table 4; Fig. 3a, b).

\section{Discussion}

Spisulosine, a compound of marine origin, which has antitumor activity in preclinical models [1, 6], was studied as a weekly 3-h i.v. infusion in doses ranging from 4 to $200 \mathrm{mg} / \mathrm{m}^{2}$. This schedule was generally well tolerated, as illustrated by the low incidence of drug-related grade 3/4 or serious adverse events. Of note, three patients had grade 3 AST increases, and 2 patients had grade 3 ALT increases, one of these adverse drug reactions qualifying as the only DLT observed in this trial. These safety findings are consistent with preclinical investigations and other early clinical studies [6-9], with reversible transaminase increases reported at the highest doses in concurrent phase I clinical trials with Spisulosine using 3 and 24-h i.v. infusions every 3 weeks.

As was the case with the 24-h every 3 -week schedule, infusion site reactions were relatively common in this study but did not require dose or schedule modifications. Preclinical toxicity studies suggested that cardiotoxicity could be dose limiting for this compound, but this was not confirmed in our clinical series. Overall, the toxicity profile was consistent between the different administration schedules, with notable toxicities being mainly hepatic and neurological.

Drug-related neurotoxicity has been a common feature in a number of clinical studies with various compounds of natural origin and especially with some marine agents [14, 15]. The neurological events observed in the Phase I program of Spisulosine include cases of sensory or motor neuropathy, neuropathic pain, dizziness, apraxia, aphasia, headache, somnolence, tremor, and decreased level of consciousness. One patient treated with Spisulosine $200 \mathrm{mg} / \mathrm{m}^{2}$ as a $24-\mathrm{h}$ i.v. infusion developed grade 3 drug- related central neurotoxicity, which led to the patient's death 6 days after the first administration of the experimental agent [6]. The neurotoxic potential of the drug was confirmed in our study. Of note, the neurotoxicity of Spisulosine was described as being more acceptable in another Phase I trial [7]. The pathophysiology of the neurotoxicity of the agent is currently unknown.

The PK profile of Spisulosine in this schedule showed a wide distribution and a long terminal half life, with no evidence of clinically relevant accumulation and a biexponential elimination phase. There was an apparent linear relationship between Spisulosine dose and exposure according to $C_{\max }$ and AUC.

Recruitment of patients to Spisulosine clinical trials was discontinued during exploration of the last dose level in this study, due to an unfavorable risk/benefit balance, and due to the absence of clinically meaningful antitumor efficacy in the whole clinical program. At that time, only short-lasting stable disease had been reported as efficacy signal from these trials. The seriousness of the neurological toxicity experienced by one patient [6] supported this decision.

In our trial, further patient recruitment and the expansion of the recommended dose cohort were not implemented for ethical reasons. The MTD for this schedule can be estimated to be $200 \mathrm{mg} / \mathrm{m}^{2} /$ day or higher. There was no convincing preliminary evidence of clinical antitumor efficacy.

In conclusion, hepato- and neurotoxicity are likely dose limiting for Spisulosine in the weekly 3-h schedule, which is in line with the results of other phase I trials and led to discontinuation of the clinical development of this marine compound.

Acknowledgments We are grateful to the patients who participated in this trial, the many clinical research associates, nurses, and data managers for their help in patient recruitment, data management, and patient care during the conduct of this trial. This work was supported by PharmaMar SA, Spain.

\section{References}

1. Faircloth G, Cuevas C (2006) Kahalalide F and ES285: potent anticancer agents from marine molluscs. Prog Mol Subcell Biol 43:363-379

2. Baird R, Clarke P, Workman P (2005) ES-285, a novel marine anticancer agent: Investigation of mechanism of action using gene expression microarrays. AACR Meet Abstr 2005:970

3. Sanchez AM, Malagarie-Cazenave S, Olea N, Vara D, Cuevas C, Diaz-Laviada I (2008) Spisulosine (ES-285) induces prostate tumor PC-3 and LNCaP cell death by de novo synthesis of ceramide and PKCzeta activation. Eur J Pharmacol 584:237-245

4. Cuadros R, Montejo de Garcini E, Wandosell F, Faircloth G, Fernandez-Sousa JM, Avilla J (2000) The marine compound spisulosine, an inhibitor of cell proliferation, promotes the disassembly of actin stress fibers. Cancer Lett 152:23-29 
5. Salcedo M, Cuevas C, Alonso JL, Otero G, Faircloth G, Fernandez-Sousa JM, Avila J, Wandosell F (2007) The marine sphingolipid-derived compound ES 285 triggers an atypical cell death pathway. Apoptosis 12:395-409

6. Baird RD, Kitzen J, Clarke PA, Planting A, Reade S, Reid A, Welsh L, Lopez Lazaro L, de las Heras B, Judson IR, Kaye SB, Eskens F, Workman P, de Bono JS, Verweij J (2009) Phase I safety, pharmacokinetic, and pharmacogenomic trial of ES-285, a novel marine cytotoxic agent, administered to adult patients with advanced solid tumors. Mol Cancer Ther 8:1430-1437

7. Vilar E, Grünwald V, Schöffski P, Singer H, Salazar R, Iglesias JL, Casado E, Cullell-Young M, Baselga J, Tabernero J (2010) A phase I dose-escalating study of ES-285, a marine sphingolipidderived compound, with repeat dose administration in patients with advanced solid tumors. Invest New Drugs. doi:10.1007/ s10637-010-9529-9

8. Schöffski P, Grünwald V, Giaccone G et al (2008) Outcome of three Phase I trials of the marine compound ES-285 (3 hour infusion) in patients with refractory solid tumors. Eur J Cancer, 6(12), ENA Meet Abstr 176

9. Massard C, Majem M, Soria J-C, Salazar R, Deutsch E, Garcia M, Oaknin A, Soto A, de las Heras B, Armand J-P (2007) Phase I (3 hour infusion every 3 weeks) escalating dose study of intravenous ES-285 in patients with advanced malignant solid tumors. AACR Meet Abstr 2007:A4

10. Therasse P, Arbuck SG, Eisenhauer EA, Wanders J, Kaplan RS, Rubinstein L, Verweij J, Van Glabbeke M, van Oosterom AT,
Christian MC, Gwyther SG (2000) New guidelines to evaluate the response to treatment in solid tumors. European Organization for Research and Treatment of Cancer, National Cancer Institute of the United States, National Cancer Institute of Canada. J Natl Cancer Inst 92:205-216

11. Den Brok MW, Nuijen B, Meijer DM, Millan E, Manada C, Beijnen JH (2005) Pharmaceutical development of a parenteral lyophilised formulation of the investigational anticancer agent ES-285.HCl. PDA J Pharm Sci Technol 59:246-257

12. Den Brok MW, Nuijen B, Garcia JL, Miranda E, Calvo P, Manada C, Beijnen JH (2006) Compatibility and stability of the novel anticancer agent ES-285 $\times \mathrm{HCl}$ formulated with 2-hydroxypropyl-beta-cyclodextrin in infusion devices. Pharmazie 61:21-24

13. Stokvis E, Nan-Offeringa L, Rosing $H$, Lopez-Lazaro L, Acena JL, Miranda E, Lyubimov A, Levine BS, D'Aleo C, Schellens JH, Beijnen JH (2003) Quantitative analysis of ES-285, an investigational marine anticancer drug, in human, mouse, rat, and dog plasma using coupled liquid chromatography and tandem mass spectrometry. J Mass Spectrom 38:548-554

14. Geldof AA, Mastbergen SC, Henrar RE, Faircloth GT (1999) Cytotoxicity and neurocytotoxicity of new marine anticancer agents using in vitro assays. Cancer Chemother Pharmacol 44(4):312-318

15. Le Tourneau C, Raymond E, Faivre S (2007) Aplidine: a paradigm of how to handle the activity and toxicity of a novel marine anticancer poison. Curr Pharm Des 13(33):3427-3439 